\title{
A comparative study of Kaposi's sarcoma and granuloma pyogenicum in Uganda
}

\author{
F. D. LEE \\ From the University Departments of Pathology, Western Infirmary, Glasgow, and \\ Makerere University College, Kampala, Uganda
}

SYNOPSIS A comparison has been made between two vasoformative lesions, Kaposi's sarcoma and granuloma pyogenicum, as they are encountered in Uganda. Both are predominantly skin lesions arising in the distal extremities, may resemble each other clinically, and are widespread in their distribution in Ugandan communities. They bear a reciprocal relationship to each other as regards age and sex incidence, Kaposi's sarcoma being mainly a disease of adult males and granuloma pyogenicum a disease of immature males and females. Histologically there are many similarities between them, the essential difference being the presence of a spindle-cell sarcomatous element in Kaposi's sarcoma. The clinical behaviour reflects this difference in that granuloma pyogenicum develops quickly and appears to be self-limiting, while Kaposi's sarcoma is slowly progressive and shows much less tendency to regress.

On the basis of these findings it is concluded that, although these two lesions may be completely unrelated, it is possible that both represent a response of the vasoformative elements in the skin to a similar form of initiating stimulus and that hormonal or sex-linked genetic factors determine which lesion will develop in response to this stimulus.

The presence of intracytoplasmic inclusion in the tumour cells of Kaposi's sarcoma might be of significance in the histogenesis of this tumour, and of value in its histological differentiation from granuloma pyogenicum.

Kaposi's sarcoma is a common tumour in many parts of Africa and comprises about $4 \%$ of all malignant tumours in Uganda (Davies, Elmes, Hutt, Mtimavalye, Owor, and Shaper, 1964). The aetiology and pathogenesis are unknown, and even the histogenesis remains a matter of dispute. With practice, however, the histological diagnosis is relatively straightforward although difficulties are encountered with anaplastic variants of the tumour. It is obviously important to distinguish Kaposi's sarcoma from other malignant spindle-cell tumours, and even more so to recognize that it may resemble reactive non-neoplastic conditions. Of the latter group, the so-called granuloma pyogenicum is the most important. This actively vasoformative lesion, often removed as a 'skin tumour' in Uganda, bears considerable histological resemblance to, and has some interesting clinical and epidemiological relationships with, Kaposi's sarcoma, and the present study was undertaken to establish a possible association between these two conditions.

Received for publication 20 July 1967.
METHODS AND MATERIALS

This study comprises two parts: (1) an epidemiological survey of Kaposi's sarcoma and granuloma pyogenicum, including relevant clinical features, and (2) a histological comparison between the two lesions.

All the cases studied were from the surgical pathology files of the Pathology Department, Makerere Medical School, Kampala, Uganda, during the period 1965-66. Ninety-one consecutive cases of Kaposi's sarcoma diagnosed after 1 January 1965 were analysed, together with 47 cases of granuloma pyogenicum diagnosed after the same date, cases with doubtful histological findings or inadequate clinical details being, however, excluded. This study is mainly concerned with skin lesions: those arising from viscera, lymph nodes, or mucous membranes are not included. The information required in each case comprised the age of the patient at the time of biopsy, sex, the race and tribe, the site of the lesion(s), and the duration of the history. Since many of the biopsies, however, came from patients in outlying districts of Uganda, it was not always possible to obtain an accurate history, and in only $65 \%$ of cases of granuloma pyogenicum and $54 \%$ of cases of Kaposi's sarcoma was there reliable information as to the duration of the lesions. 
The initial histological diagnosis in every case was confirmed using standard paraffin sections stained by haemalum-eosin (HE). Representative cases from each group were selected for more detailed study by a range of staining techniques, which included Mallory's phosphotungstic acid-haematoxylin (PTAH), periodic acidSchiff (PAS) before and after diastase, Masson's trichrome, Verhoeff-van Gieson for elastica and collagen, Gomori's aldehyde fuchsin for elastica, the phosphotannin silver impregnation method for reticulin (Slidders, Fraser, and Lendrum, 1958), Perl's Prussian blue reaction for haemosiderin, the Feulgen reaction for deoxyribonucleic acid, methyl-green pyronin for ribonucleic acid, Gram-Weigert, phloxin-tartrazine (Lendrum, 1947), the Rhoda-Coomassie method (Lendrum, Fraser, Slidders, and Henderson, 1962), Mann's methylene-blue eosin, and Machiavello's basic fuchsin-citric acid-methylene blue. The last four stains were employed for the demonstration of inclusion bodies.

\section{EPIDEMIOLOGICAL AND CLINICAL SURVEY}

The important features referable to the age, sex, and tribe of the patients, and the site and duration of the lesions in both conditions are summarized in Tables I-IV.

AGE Either lesion can develop at any age from early childhood onwards although in both instances the youngest patient in my series was 3 years old. The mean age at biopsy for Kaposi's sarcoma $(42.0 \mathrm{yr})$ is much greater than that for granuloma pyogenicum (28.2 yr). This difference in age incidence is even more marked when males are considered separately (Tables I and II); only $23 \%$ of males with Kaposi's sarcoma were aged $30 \mathrm{yr}$ or less, whereas $63 \%$ of males with granuloma pyogenicum were below this age at the time of diagnosis. Considering the age structure of the Uganda African population (the mean age at death in adults from a personal series of necropsies was $42 \mathrm{yr}$ ), it is likely that Kapsoi's sarcoma increases in incidence with advancing age. Differences in age incidence between the two lesions are less striking with female patients, although it should be mentioned that the majority of females $(77 \%$ ) with Kaposi's sarcoma were over 40 years of age.

\section{TABLE I}

SEX AND AGE INCIDENCE OF 100 CASES OF KAPOSI'S SARCOMA AND 47 CASES OF GRANULOMA PYOGENICUM IN UGANDA AND LENGTH OF HISTORY BEFORE BIOPSY

\begin{tabular}{lll} 
& $\begin{array}{c}\text { Kaposi's } \\
\text { Sarcoma }\end{array}$ & $\begin{array}{c}\text { Granuloma } \\
\text { Pyogenicum }\end{array}$ \\
\hline Sex ratio (male : female) & $9 \cdot 1: 1 \cdot 0$ & $1 \cdot 2: 1 \cdot 0$ \\
Mean age (all cases) & $42 \cdot 0 \mathrm{yr}$ & $28 \cdot 2 \mathrm{yr}$ \\
Mean age (male cases) & $41 \cdot 7 \mathrm{yr}$ & $25 \cdot 5 \mathrm{yr}$ \\
Mean age (female cases) & $44 \cdot 9 \mathrm{yr}$ & $31 \cdot 4 \mathrm{yr}$ \\
Length of history & $12 \cdot 2 \mathrm{months}$ & $4 \cdot 3$ months
\end{tabular}

TABLE II

AGE AND SEX DISTRIBUTION OF KAPOSI'S SARCOMA AND GRANULOMA PYOGENICUM BY DECADES

\begin{tabular}{|c|c|c|c|c|c|c|}
\hline \multirow[b]{2}{*}{ Decade (yr) } & \multicolumn{3}{|c|}{ Kaposi's Sarcoma (\%) } & \multicolumn{3}{|c|}{ Granuloma Pyogenicum (\% } \\
\hline & All Cases & Males & Females & All Cases & Males & Females \\
\hline $0-9$ & 1 & 1 & - & 13 & 11 & 2 \\
\hline $10-19$ & 3 & 3 & - & 23 & 15 & 9 \\
\hline $20-29$ & 19 & 16 & 2 & 13 & 9 & 4 \\
\hline $30-39$ & 22 & 22 & - & 28 & 9 & 19 \\
\hline $40-49$ & 22 & 19 & 3 & 9 & 6 & 2 \\
\hline $50-59$ & 16 & 13 & 3 & 9 & 4 & 4 \\
\hline $60-69$ & 8 & 7 & 1 & 4 & - & 4 \\
\hline $70-79$ & 5 & 5 & - & 2 & 2 & - \\
\hline $80-89$ & 2 & 2 & - & - & - & 一 \\
\hline \multirow[t]{2}{*}{ Over 90} & 1 & 1 & - & - & - & - \\
\hline & 100 & 90 & 10 & 100 & 56 & 44 \\
\hline
\end{tabular}

SEX DISTRIBUTION The predilection of Kaposi's sarcoma for males both in Europeans (Choisser and Ramsey, 1939) and in Africans (Lothe, 1960) is again noted in this series; $90 \%$ of my cases were in male patients. With granuloma pyogenicum, the sex incidence is about equal although there is an excess of males under the age of $30 \mathrm{yr}(16: 7)$ and an excess of females $(14: 10)$ over this age.

Summarizing the combined data from age and sex incidence studies, it would appear that the two lesions bear a reciprocal relationship to each other, granuloma pyogenicum tending to be more prevalent in those groups in which Kaposi's sarcoma is uncommon and vice versa. Thus, although the great majority of cases of Kaposi's sarcoma is found in males over the age of $30 \mathrm{yr}$, granuloma pyogenicum is relatively uncommon in this group.

TRIBAL Distribution The Pathology Department at Makerere received surgical biopsies from all parts of Uganda, and it is thus possible to obtain a fairly accurate assessment of the tribal incidence of the two conditions. Although there are some minor differences, the overall pattern of distribution is essentially similar. The largest Ugandan tribe, the Baganda (Bantu), comprise about one-fifth of

TABLE III

TRIBAL DISTRIBUTION OF KAPOSI'S SARCOMA AND GRANULOMA PYOGENICUM

Kaposi's Sarcoma (\%) Granuloma Pyogenicum (\%)

\begin{tabular}{lrrrrrrr}
\cline { 6 - 7 } Tribe & All Cases & Males & Females & & All Cases & Males & Females \\
\hline Ganda & 29 & 24 & 4 & 21 & 11 & 10 \\
Ankole & 9 & 9 & - & 6 & 4 & 2 \\
Toro & 3 & 2 & 1 & 4 & 2 & 2 \\
Hutu & 3 & 3 & - & 6 & 6 & - \\
Atesot & 1 & 1 & - & 9 & 9 & - \\
Lango & 4 & 4 & - & 2 & - & 2 \\
Soga & 3 & 2 & 1 & 2 & - & 2 \\
Kiga & 9 & 8 & 1 & 11 & 5 & 6 \\
Nyoro & 1 & 1 & - & 4 & -19 & 4 \\
Others & 37 & 35 & 2 & 34 & 19 & 15 \\
& 100 & 90 & 10 & 100 & 56 & 44
\end{tabular}


the population of Uganda and account for 20 to $30 \%$ of cases of both conditions, and all the other major tribal grouping are represented in both series (Table III). It may be reasonably concluded that both Kaposi's sarcoma and granuloma pyogenicum are widely distributed lesions in Uganda and that they coexist within individual communities.

SITE OF THE LESIONS There is a marked similarity in the distribution of the initial lesions between the two conditions. The distal parts of the limbs, particularly the lower extremities, are predominantly involved, although the hands and the fingers are more often affected in granuloma pyogenicum than in Kaposi's sarcoma (Table IV). There is no clear relationship between site of origin and sex and age distribution as regards skin lesions in either condition. In two males (aged $50 \mathrm{yr}$ and $59 \mathrm{yr}$ respectively) there was tumour in the inguinal lymph nodes associated with lesions on the feet. The multiplicity of the skin lesions is a characteristic feature of Kaposi's sarcoma, and was found in $40 \%$ of my cases at the time of diagnosis. In only one case of granuloma pyogenicum (a 45-year-old male) was there more than one lesion.

\section{TABLE IV}

SITUATION OF INITIAL LESIONS IN KAPOSI'S SARCOMA AND GRANULOMA PYOGENICUM ${ }^{1}$

\begin{tabular}{lll} 
Site & $\begin{array}{c}\text { Kaposi's } \\
\text { Sarcoma }(\%)\end{array}$ & $\begin{array}{l}\text { Granuloma } \\
\text { Pyogenicum (\%) }\end{array}$ \\
\hline Lower limbs only & 69 & 49 \\
Upper limbs only & 12 & 45 \\
Lower and upper limbs & 7 & -6 \\
Trunk & $\frac{6}{2}$ & -
\end{tabular}

${ }^{1}$ In one case of Kaposis sarcoma the patient presented with lesions all over the body this case is not included in the table.

DURATION OF LESIONS The mean duration of the history in Kaposi's sarcoma before diagnosis (12.2 months) is suggestive of a slowly developing lesion. Granuloma pyogenicum is much more rapid in evolution, and the mean length of the history was only 4.2 months. In $77 \%$ of cases the lesion had been present for three months or less before excision, whereas in only $43 \%$ of cases of Kaposi's sarcoma was there such a short history. These findings suggest that Kaposi's sarcoma, although developing slowly, shows little tendency to regress and the patient is ultimately forced to seek medical attention, whereas granuloma pyogenicum because of its rapid growth demands treatment sooner and appears to be self-limiting, otherwise one would expect to see many more cases of longer duration, particularly in an underdeveloped country.
HISTOLOGY

KAPOSI'S SARCOMA The histological appearance of this neoplasm has been the subject of many critical surveys such as those of Pautrier and Diss (1929), Dörffel (1932), Aegerter and Peale (1942), and Tedeschi (1958) in Europe and America, and of Kaminer and Murray (1950) and Lothe (1960) in Africa. It is not my intention to present a further detailed description but to re-emphasize certain aspects of the histopathology which are relevant to this study. Although much has been written of the bizarre variability in the features of Kaposi's sarcoma, most of the cases in my series presented fairly uniform features with a clearly recognizable spindle-cell sarcomatous element. Earlier 'granulomatous' or 'angiomatous' stages as described by Dörffel and others are not conspicuous; these stages do not appear to be a feature of African cases (Kaminer and Murray).

Kaposi's sarcoma usually arises in the deeper parts of the dermis, although sometimes the lesion is more superficial and even polypoid in structure. Ulceration had taken place in $30 \%$ of my cases and appeared to be related more to the site than

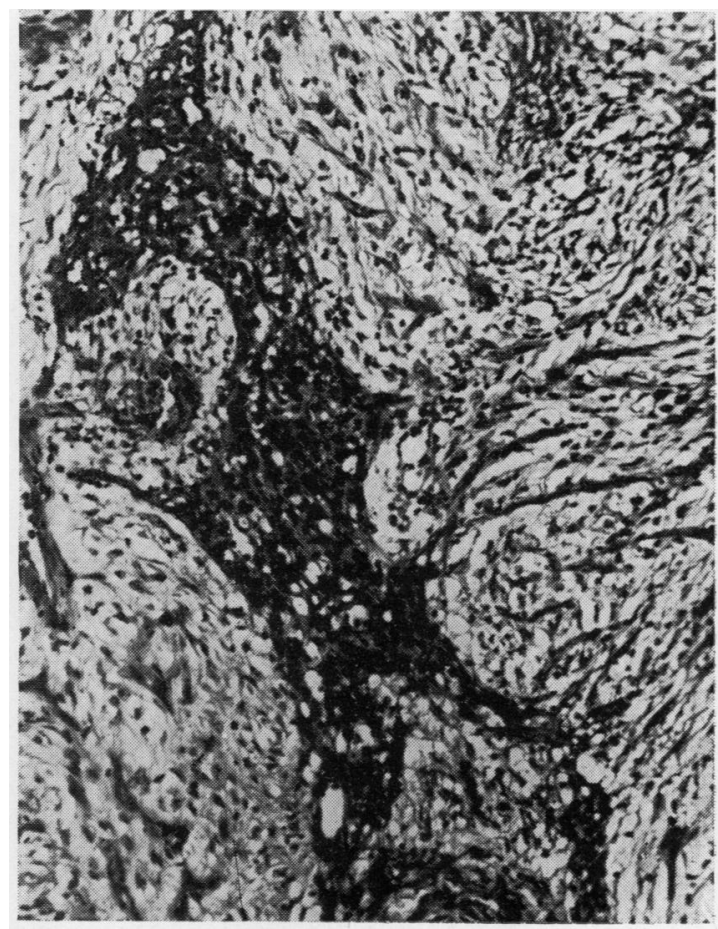

FIG. 1. Kaposi's sarcoma. An area of granulation tissue with vessels of capillary type clearly arising from a mass of tumour tissue. Masson's trichome $\times 560$ 


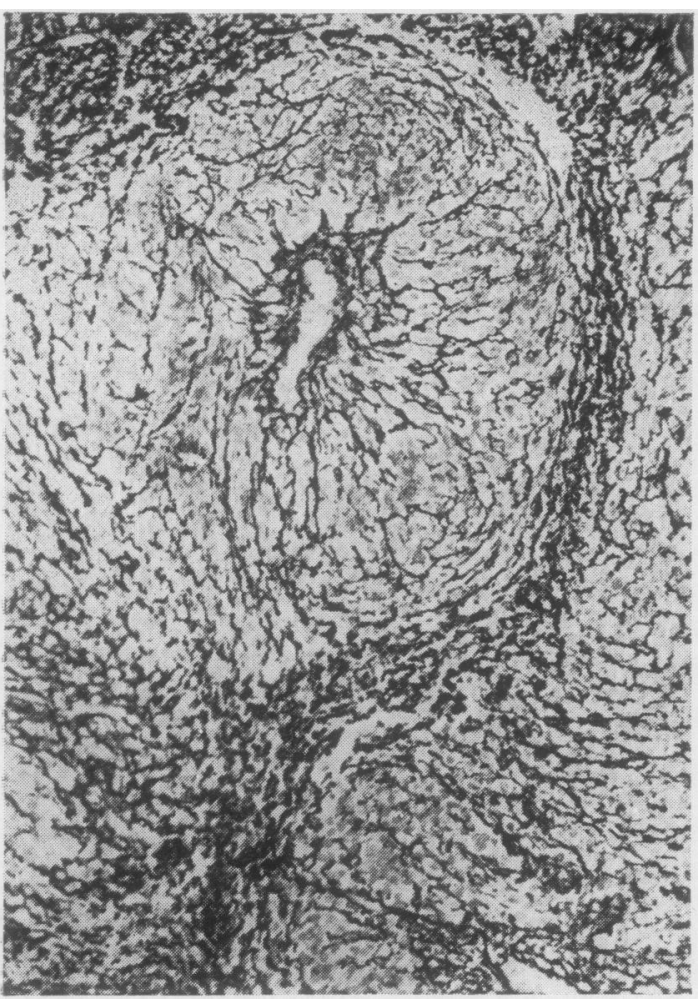

FIG. 2

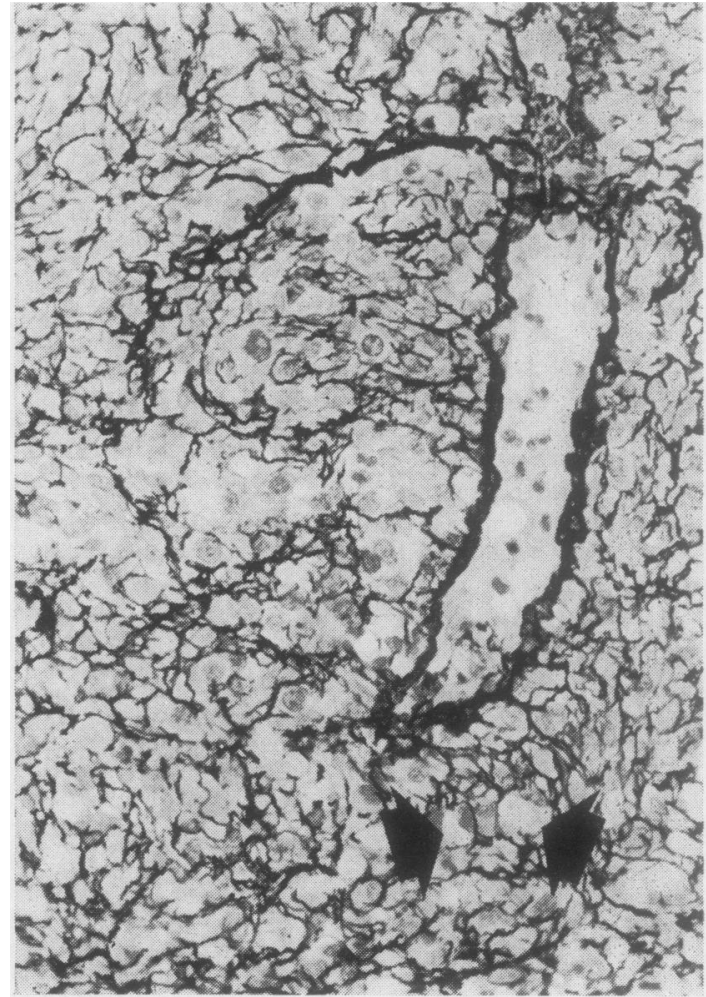

FIG. 3
FIG. 2. Kaposi's sarcoma. The tumour has a distinctly lobulated pattern with sheets of vascular channels orientated around a central arteriole. Reticulin $\times 140$.

FIG. 3. Kaposi's sarcoma. A less well-differentiated variant of the tumour showing 'canalization' of the tumour cells (arrowed). An individual cell may share part of its reticulin sheath with neighbouring cells. Reticulin $\times 210$.

FIG. 4. Kaposi's sarcoma. Individual vascular channels lined by tumour cells and separated by hyalinized connective tissue, possibly a manifestation of tumour regression. Intracytoplasmic inclusions are also visible (arrowed). Haemalum-eosin $\times 840$. 
to the duration of tumour growth. When ulceration does take place, however, the granulation tissue which forms on the surface appears to derive its vascular component from the underlying tumour tissue (Fig. 1), a feature which emphasizes the vasoformative nature of the neoplasm. The tumour itself consists of intertwining bundles or sheaves of spindle cells and the formation of vascular spaces containing red cells is usually conspicuous. Reticulin stains have been employed by other workers such as Lothe (1960). My own studies reveal a distinctly lobulated pattern and outline sheets of closely packed vascular channels spreading outwards from a central vessel like the rays of a sunburst (Fig. 2). This central vessel appears to be an arteriole with poorly developed elastic tissue, although it has yet to be established that it actually forms part of the tumour. The obviously neoplastic vascular spaces appear to be either formed within, or surrounded by, individual tumour cells, each of which is contained within a reticulin sheath shared by contiguous cells. A vessel thus formed may also share at least part of its reticulin sheath with neighbouring channels (Fig. 3); this is also true of the more obviously 'angiomatous' parts of the lesion, although in more mature (and possibly regressing) lesions the channels may be widely separated by hyalinized fuchsinophilic connective tissue (Fig. 4). Reticulin formation is, however, much less prominent in anaplastic variants of the tumour.

The nuclei of tumour cells are ovoid in shape and have a stippled chromatin pattern; nucleoli are seldom prominent, but there is a variable degree of nuclear pleomorphism and mitoses are easily found. Most cells have a moderate amount of cytoplasm which is faintly basophilic and occasionally pyroninophilic. In other $60 \%$ of cases, eosinophilic intracytoplasmic inclusions can be demonstrated. They are clearly visible in HE-stained sections, although sometimes difficult to distinguish from red cells. Spheroidal in shape, they are usually multiple and may be of any size up to 10 microns in diameter (Fig. 5). In their staining properties they resemble fibrin, in that they appear deep blue-black with PTAH and bright orange-red with Masson's trichrome. They are moderately PAS-positive before and after diastase, Grampositive, methyl-green positive, and Feulgennegative. Both the phloxin-tartrazine and RhodaCoomassie methods stain the inclusions beautifully and in the former case they withstand prolonged differentiation which would be expected to decolorize fibrin (Lendrum, 1947). The only other structures retaining phloxinophilia in the sections under these circumstances are keratin and the granules of plasma cells (Russell bodies). There can be no doubt that these inclusions are present in the cytoplasm of tumour cells, although sometimes they appear to lie free in neoplastic vascular spaces. Tumour cells packed with inclusions may show nuclear pyknosis and distortion indicative of degeneration, and sometimes protrude into a vascular space in such a way as to suggest desquamation into the lumen; particles lying free within vessels probably derive from disintegration of these cells.

Certain other well-recognized features should be mentioned. The tumour shows some variation in gross architecture, sometimes forming lobulated, and even polypoid, masses, and sometimes being of a more diffuse and infiltrative character; small satellite nodules are frequently found. The growth is subdivided by connective tissue septa which carry arterioles and other vessels. Around the tumour, the dermal or subcutaneous tissues may be grossly oedematous, and numerous cavernous vascular channels, which may be venous or lymphatic in type and presumably drain the tumour, may form a 'ring' around the tumour mass, particularly in the subepidermal zone (Fig. 6). If there is an abundant hyalinized stroma in or around the tumour it is usually a consequence of necrosis or haemorrhage; and haemosiderin granules can often be demonstrated either within macrophages or in tumour cells. Occasionally metaplastic bone formation is noted in the stroma. Lymphocytic, histiocytic, or plasma-cell infiltration is a conspicuous feature of Kaposi's sarcoma; and perivascular infiltrates of these cells are often noted around tumour masses (Fig. 7). Plasma cells may also be found within the tumour, so closely intermingled indeed that it may be difficult to distinguish them from tumour cells. There is, however, no reason to believe that these 'inflammatory' changes are other than of a secondary nature.

GRANUlOMA PYOgenicum This lesion is wellrecognized throughout the world and its histological structure is distinctive. It is invariably raised above the skin surface and in almost every case ulceration has taken place by the time the biopsy is taken (Fig. 8). The raised and almost polypoid nature of the lesion is characteristic; the changes seldom extend more deeply than the upper dermis, and in general granuloma pyogenicum is a more superficial lesion than Kaposi's sarcoma. This probably accounts for its more frequent ulceration. Many observers refer to a 'collar' of hyperplastic squamous epithelium around the margin of the nodule, which is well circumscribed.

Two distinct types of histological change can typically be demonstrated. Immediately beneath the 

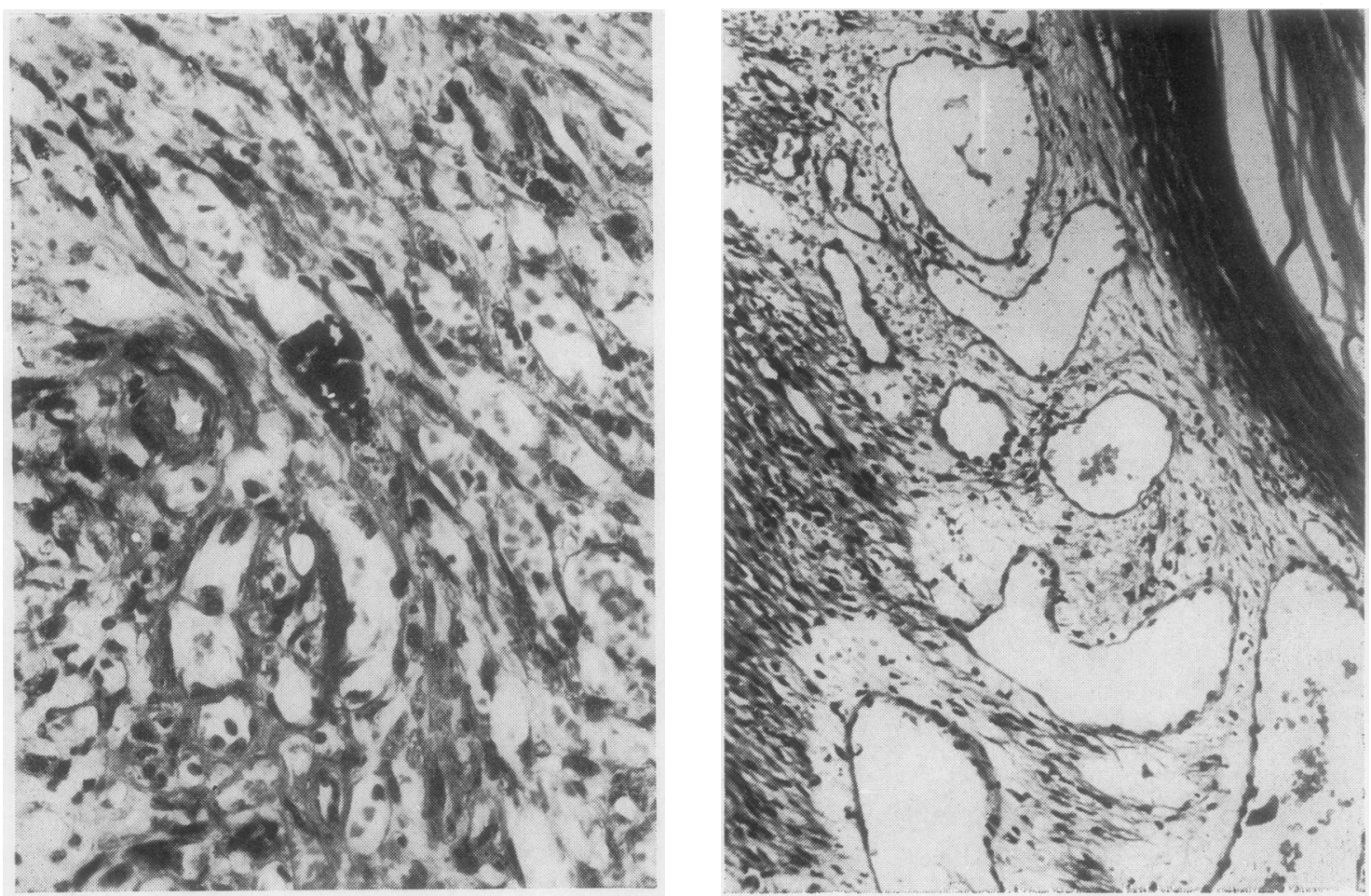

FIG. 5

FIG. 6

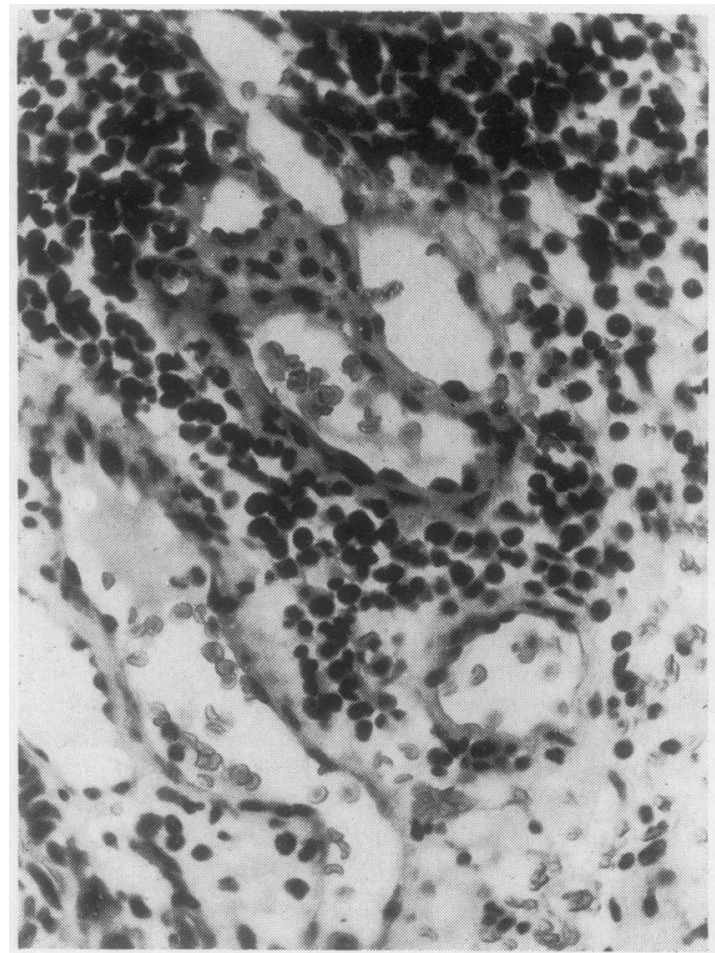

FIG. 5. Kaposi's sarcoma.

Intracytoplasmic spheroidal inclusions of variable size within tumour cells. Phosphotungstic acid haematoxylin $\times 840$.

FIG. 6. Kaposi's sarcoma. Cavernous draining vessels, which may be either of venous or lymphatic type, lying between the periphery of the tumour and the epidermis. $H E \times 140$.

FIG. 7. Kaposi's sarcoma.

Perivascular infiltration of plasma cells and lymphocytes at the periphery of the tumour. Masson's trichrome $\times 840$.

FIG. 7 

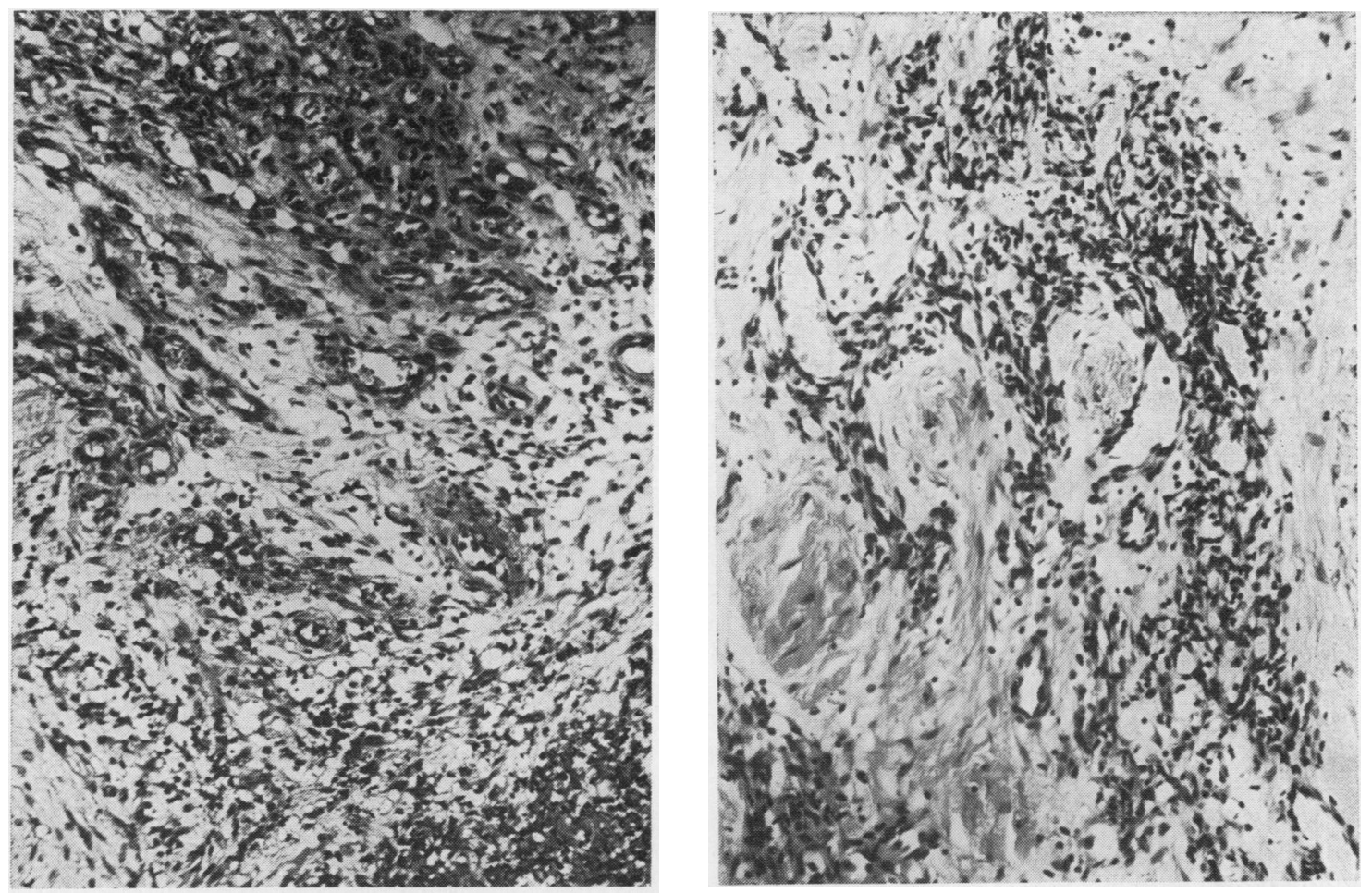

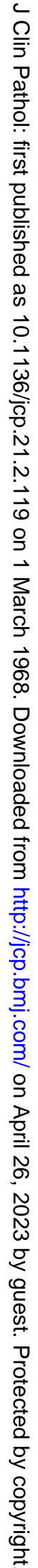

FIG. 8

FIG. 9

FIGS. 8 and 9. Granuloma pyogenicum. Granulation tissue in the zone of ulceration, the capillaries appearing to rise from the angiomatoid component of the lesion (Fig. 8), which, in Fig. 9, is seen embedded in dense scar-like tissue. Figure 8 haematoxylin and eosin; Fig. 9 Masson. Both $\times 140$.
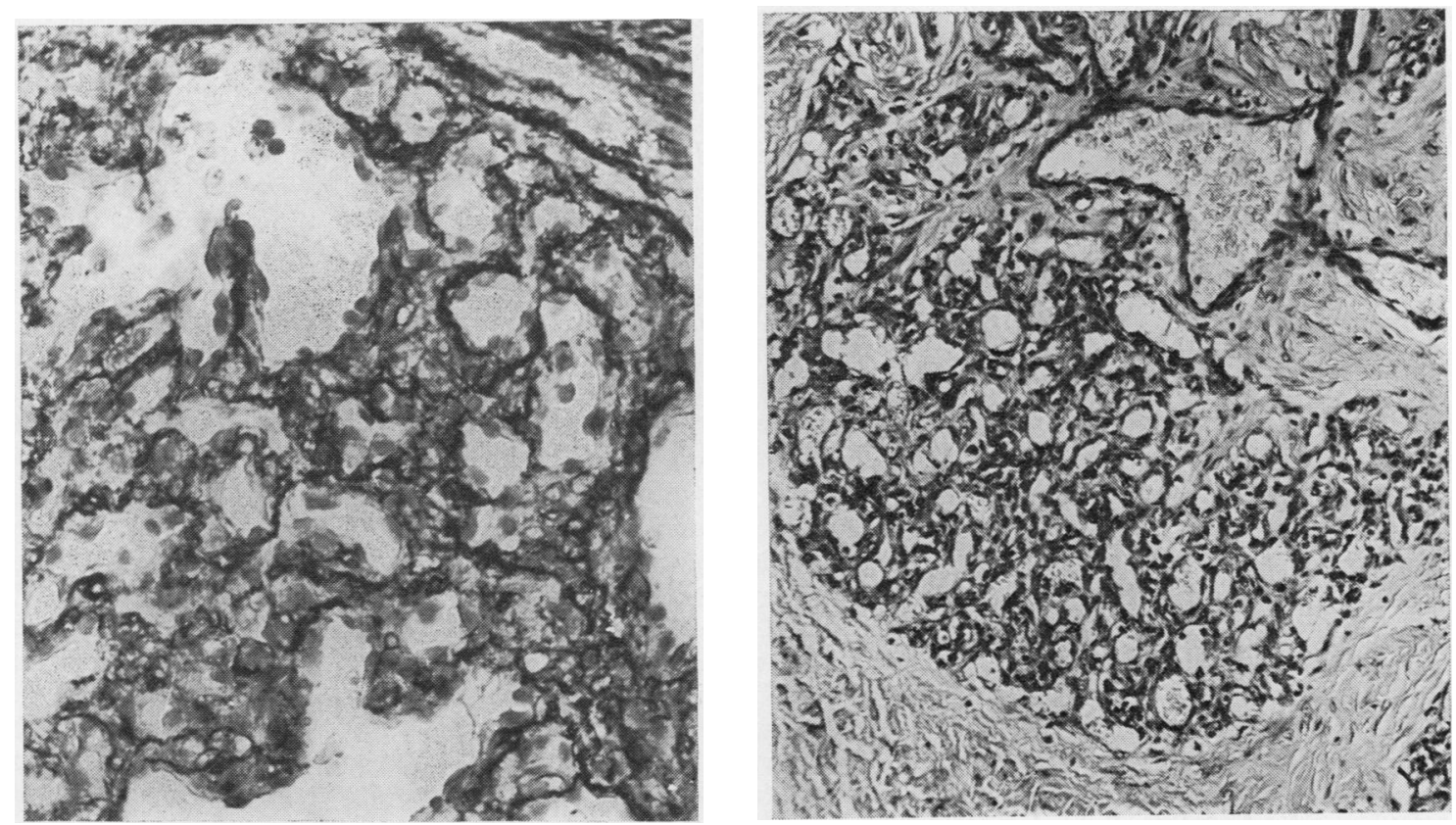

FIG. 10

FIG. 11

FIGS. 10 and 11. Granuloma pyogenicum. The reticulin pattern is complex, but capillary channels at various stages of differentiation are visible (Fig. 10); the characteristic angiomatoid component, the vessels appearing to drain into a large, central, cavernous channel (Fig. 11). Figure 10 reticulin $\times 560$; Fig. 11 Masson's trichrome $\times 140$. 
ulcerating surface (which shows fibrinous exudation and neutrophil infiltration) there is a zone of true granulation tissue formation with capillaries and arterioles (occasionally showing fibrinoid necrosis or thrombosis) running at right angles to the surface and interspersed with loose fibroblastic tissue. Deep to this zone is the core (and sine qua non) of the lesion consisting of lobules of 'angiomatoid' tissue lying in a loose, oedematous connective tissue mantle and often surrounded by a dense fibrous stroma resembling scar tissue or even keloid (Fig. 9). There is usually some infiltration of lymphocytes, plasma cells, and eosinophils both within the lesion and around the periphery, often with a perivascular distribution.

The angiomatoid component of this deeper tissue consists of groups of largely immature capillaries with plump active endothelial cells (Fig. 9) which may show mitotic activity. The vessels are surrounded by a fine reticulin sheath (Fig. 10), and in some cases appear to be draining into a large cavernous channel lying centrally (Fig. 11); similar channels may be seen around the periphery, often associated with chronic inflammatory infiltration. It is notable that the capillaries of the granulation tissue close to the surface appear to arise from the underlying angiomatoid tissue. It is this latter component of the lesion which may be confused with Kaposi's sarcoma. It is emphasized, however, that although the vessels in granuloma pyogenicum lie in close proximity to one another, they are usually separated by a matrix of loose connective tissue, unlike the neoplastic channels in Kaposi's sarcoma (Fig. 3). A spindle-cell element is also lacking. Haemosiderin deposition is inconspicuous. Intracytoplasmic inclusions are not found in granuloma pyogenicum, and their presence is therefore of some value in its differentiation from Kaposi's sarcoma.

\section{DISCUSSION}

A comparison has been made between two potentially vasoformative skin lesions, granuloma pyogenicum and Kaposi's sarcoma, as they are encountered in Uganda, the purpose being to establish the nature of their relationship to each other. Three possible types of relationship require to be seriously considered:

1 The only association between the two lesions lies in their undoubted histological and clinical similarity, which may give rise to difficulties in differentiation. This must be regarded as the present position with regard to these conditions, and the differences in age and sex incidence, and to some extent site distribution, may be cited to support this view.

2 Granuloma pyogenicum represents a benign, self-limiting version of Kaposi's sarcoma, a relationship not unlike that existing between molluscum sebaceum and invasive squamous carcinoma (Lancet, 1953; Whiteley, 1957; Ghadially, 1958; Lennox, 1960). This implies that they are the same condition modified by exogenous or endogenous factors. This is unlikely, since granuloma pyogenicum has a world-wide distribution and is not uncommon in northern Europe, whereas Kaposi's sarcoma has a more restricted geographical distribution (see Lothe, 1960).

3 A similar form of initiating stimulus leads to the development either of granuloma pyogenicum or Kaposi's sarcoma, and that hormonal factors or sex-linked genetic factors determine which lesion will develop in response to this stimulus. Thus in females or immature males damage to the vasoformative elements of the skin (and elsewhere) tends to produce a rapidly growing but self-limiting lesion (granuloma pyogenicum); while in adult males this results in a more slowly growing but progressive and histologically malignant neoplasm (Kaposi's sarcoma). This would account for the relative dearth of cases of granuloma pyogenicum in adult males, a finding otherwise difficult to explain in an apparently trauma-related lesion (vide infra). I believe that the evidence I have presented accords with this hypothesis.

EPIDEMIOLOGICAL AND AETIOLOGICAL CONSIDERATIONS Epidemiological studies reveal that both Kaposi's sarcoma and granuloma pyogenicum are predominantly skin lesions of the extremities, which (as their similar tribal distribution indicates) appear to coexist within East African communities and could have common initiating causes. The evidence that trauma is of importance in the causation of Kaposi's sarcoma in Uganda is inconclusive (Lothe, 1960); on the other hand, granuloma pyogenicum often appears to be related to trauma, probably with superimposed pyogenic infection (Ormsby and Montgomery, 1954; Ronchese, 1965), and the presence histologically of dense scar-like tissue (Fig. 10) supports this view. Whatever the exact initial cause of these lesions may be, their peculiar age and sex distributions suggest that their development is influenced by sex-associated factors, which could be hormonal in nature. While several authors (Davies, 1949; Clifford and Bulbrook, 1966) have questioned the hormonal patterns in male Africans, there is still little concrete evidence to show that their hormone production or serum levels are different from those of Europeans (Wang, Bulbrook, and 
Clifford, 1966). Although hormonal influences cannot be excluded as a possible cause of the extraordinary male predominance in Kaposi's sarcoma (almost unique in a non-genital tumour), sexlinked genetic factors also require to be seriously considered. That environmental or occupational factors are alone responsible (Oettle, 1963) would appear to be unlikely.

HISTOLOGY Both lesions consist of lobules or sheets of proliferating vascular tissue surrounded by a stromal network containing both arterioles and cavernous draining channels; both show variable chronic inflammatory changes both within and at the periphery of the lesions; and following ulceration the granulation tissue formed derives its capillaries from the vascular elements of the underlying lesion in both instances. Desmoplastic reaction may be seen in either disease, probably being a response to repeated trauma or infection in granuloma pyogenicum and a reaction to necrosis and haemorrhage in Kaposi's sarcoma. The essential difference between the two is the spindle-cell sarcomatous element which confers upon Kaposi's sarcoma its distinctively malignant character. Thus, irrespective of the identity of the main cell type in Kaposi's sarcoma (vide infra), both lesions appear to represent a response of potentially vasoformative elements (particularly in the skin) to some form of damage as yet unidentified. In the case of Kaposi's sarcoma this response is either malignant $a b$ initio or becomes so at some stage in its development, whereas in granuloma pyogenicum it does not exhibit any features of malignancy and may not be neoplastic at all.

It is doubtful if the frankly sarcomatous element, observed in all of my cases of Kaposi's sarcoma, is preceded by inflammatory, granulomatous, or angiomatous stages, as suggested by some observers (Dörffel, 1932; MacKee and Cipollaro, 1936). Conversely, there is some doubt as to the acquired nature of granuloma pyogenicum. In some cases the angiomatoid component of the lesion appears to be covered by intact epidermis suggesting that its development may on occasion precede ulceration; and some favour the view that granuloma pyogenicum represents a haemangioma which has undergone infection and ulceration (Lever, 1954). This would explain its predilection for male children and adolescents, but does not account for its age distribution in females. The short history in most cases, the relationship with trauma and certain histological features such as the superficial situation and active proliferation of immature connective tissue (Lund, 1957) suggest, however, that it is usually an acquired lesion. Nevertheless it remains a possibility that both Kaposi's sarcoma and granuloma pyogenicum develop from a common preexisting angiomatous abnormality. In this context it is of interest that Sachs, Azulay, and Convit (1947) concluded that Kaposi's sarcoma, glomus tumour, and granuloma pyogenicum have a common origin and should be classified together as varieties of 'angioblastoma'.

HISTOGENESIS There can be little doubt that granuloma pyogenicum is essentially a proliferative disorder of vascular endothelium resulting mainly in the formation of blood vessels of capillary type in varying stages of differentiation; there is less certainty about the vasoformative nature of Kaposi's sarcoma (Becker, 1963) although most workers would accept this as a basic feature. The main cell type, however, still evades identification. The reticulo-endothelial system (Dörffel, 1932; Tedeschi, 1958), the perivascular Schwann cell (Pepler, 1959; Becker, 1963), pericapillary mesenchymal cells with a potential limited to the formation of vascular structures (Lothe, 1960), and multicentric neoplastic transformation of lymphatics (Dorfman, 1963) all remain as candidates for this role.

It is, however, possible that the tumour in Africa may differ from that observed in Europeans; and it is significant that intracytoplasmic particles appear to be conspicuous only in African cases (Lothe, 1960; Camain and Quenum, 1963). They are noted in over $60 \%$ of cases of Kaposi's sarcoma in my series and may provide a clue as to the histogenesis, if not the pathogenesis, of the tumour. The marked tinctorial resemblance of these inclusions to the Russell bodies of plasma cells suggests that they may also be glycoprotein in nature (Pearse, 1949). It is even possible that they are in fact Russell bodies phagocytosed by tumour cells; and it is of interest to recall that Russell (1890) believed that the bodies he described were actually within tumour cells. It is more likely, however, that the inclusions are formed within tumour cells, possibly as a manifestation of degenerative change. A further possibility that should not be too readily dismissed is that they are viral in nature; even the presence of similar bodies in other tumours in Uganda (Davies, 1960) does not necessarily exclude this. I have observed tinctorially similar inclusions in tumours such as renal carcinoma and the 'mixed mesodermal tumour' of endometrium. In the latter case one may find obviously malignant 'stromal' cells packed with intracytoplasmic eosinophilic particles. There can be no doubt that these cells are mesenchymal in origin; they are undifferentiated in the sense that they cannot readily be put into categories, but they are not obviously vasoformative. Nevertheless 
these observations provide some support for the view that Kaposi's sarcoma (in Africa at any rate) arises from a particular type of undifferentiated mesenchymal cell.

Thus while granuloma pyogenicum appears to develop as a result of stimulation of blood vascular endothelial cells or their precursors, in Kaposi's sarcoma the stimulus extends to involve a cell at an even earlier stage of differentiation; and it is this different response to stimulation which constitutes the significant difference between them.

I wish to thank Professor M. S. R. Hutt for his encouragement and criticism in the preparation of this paper, and Dr. M. G. Lewis for supplying additional pathological material. I am also indebted to Mr. N. Russell, F.I.M.L.T., for his invaluable technical assistance.

\section{REFERENCES}

Aegerter, E. E., and Peale, A. R. (1942). Arch. Path., 34, 413. Becker, B. J. P. (1963). Symposium on Kaposi's Sarcoma, edited by L. V. Ackerman and J. F. Murray, p. 164. Karger, Basle. Camain, R., and Quenum, A. (1963). Ibid., p. 140.

Choisser, R. M., and Ramsey, E. M. (1939). Amer. J. Path., 15, 155. Clifford, P., and Bulbrook, R. D. (1966). Lancet, 1, 1228.

Davies, J. N. P. (1949). Brit. med. J., 2, 676.

(1960). Quoted by Lothe, F. Kaposi's Sarcoma in Uganda Africans. M.D. Thesis, University of Sheffield.

—, Elmes, S., Hutt, M. S. R., Mtimavalye, L. A. R., Owor, R., and Shaper, L. (1964). Brit. med. J., 1, 259.
Dörffel, J. (1932). Arch. Derm. Syph. (Chic.), 26, 608.

Dorfman, R. F. (1963). In Symposium on Kaposi's Sarcoma, edited by L. V. Ackerman and J. F. Murray, p. 151. Karger, Basle.

Ghadially, F. N. (1958). J. Path. Bact., 75, 441.

Kaminer, B., and Murray, J. F. (1950). S. Afr. J. clin. Sci., $1,1$.

Lancet (1953), 2, 816.

Lendrum, A. C. (1947). J. Path. Bact., 59, 399.

-, Fraser, D. C., Slidders, W., and Henderson, R. (1962). J. clin. Path., 15, 401.

Lennox, B. (1960). In Recent Advances in Pathology, edited by C. V. Harrison. 7th ed., p. 1. Churchill, London.

Lever, W. F. (1954). Histopathology of the Skin, 2nd ed., p. 424. Lippincott, Philadelphia.

Lothe, F. (1960). Kaposi's Sarcoma in Uganda Africans. M.D. Thesis, University of Sheffield.

Lund, H. Z. (1957). Tumors of the Skin (Atlas of Tumor Pathology, Sect. 1, Fasc. 2), p. 302 . Published by the Armed Forces Institute of Pathology, Washington.

MacKee, G. M., and Cipollaro, A. C. (1936). Amer. J. Cancer, 26, 1. Oettle, A. G. (1963). Symposium on Kaposi's Sarcoma, edited by iv L. V. Ackerman and J. F. Murray, p. 17. Karger, Basle.

Ormsby, O. S., and Montgomery, H. (1954). Diseases of the Skin, 8th ed., p. 837. Kimpton, London.

Pautrier, L. M., and Diss, A. (1929). Brit. J. Derm., 41, 93.

Pearse, A. G. E. (1949). J. clin. Path., 2, 81.

Pepler, W. J. (1959). J. Path. Bact., 78, 553.

Ronchese, F. (1965). Amer. J. Surg., 109, 430.

Russell, W. (1890). Brit. med. J., 2, 1356.

Sachs, W., Azulay, R. D., and Convit, J. (1947). J. invest. Derm., 8, 317.

Slidders, W., Fraser, D. S., and Lendrum, A. C. (1958). J. Path. Bact., $75,478$.

Tedeschi, C. G. (1958). Arch. Path., 66, 656.

Wang, D. Y., Bulbrook, R. D., and Clifford, P. (1966). Lancet, 2, 1342.

Whiteley, H. J. (1957). Brit. J. Cancer, 11, 196. 